Check for updates

Cite this: RSC Adv., 2018, 8, 4900

\title{
Cobalt metal-mixed organic complex-based hybrid micromaterials: ratiometric detection of cyanide $\uparrow$
}

\author{
Hai-Bo Liu, ${ }^{*}$ He-Song Han, Bin Lan, Dong-Mei Xiao, Jing Liang, Zi-Ying Zhang \\ and Jing Wang*
}

A micrometer-sized hybrid crystalline material was facilely fabricated from the synergistic coordination chemistry of two types of 2-hydroxyazobenzene building blocks and cobalt ions. This hybrid crystalline material functioned as both receptor and signal reporter in cyanide $\left(\mathrm{CN}^{-}\right)$sensing with ratiometric absorption responses at $456 \mathrm{~nm}$ and $537 \mathrm{~nm}$. The mechanism of $\mathrm{CN}^{-}$sensing involves partial ligand dissociation accompanied by the formation of a new organic metal- $\mathrm{CN}^{-}$adduct. We believe that this protocol would be valuable in achieving the expected selectivities and sensitivities for a wide variety of analytes in many chemical and biological systems in the future.

Received 4th January 2018

Accepted 22nd January 2018

DOI: $10.1039 / \mathrm{c} 8 \mathrm{ra00079d}$

rsc.li/rsc-advances

absorption and/or emission wavelengths in the visible region

\section{Introduction}

Metal-organic hybrid nano/micromaterials have been investigated extensively in chemistry and materials science because of their desirable properties brought about by the coupling of the benefits of inorganic and organic building blocks. ${ }^{1-5}$ In recent years, anion sensing, such as cyanide $\left(\mathrm{CN}^{-}\right)$, has been one of the intriguing applications involving the design of metal-organic coordination architecture. ${ }^{6}$ Most metal complex-based $\mathrm{CN}^{-}$ sensors use metal complexes acting as both receptor and signal reporter in the presence of $\mathrm{CN}^{-}$. The following main strategies have been adopted for detecting $\mathrm{CN}^{-}$: (i) following the "displacement" approach: replacement of the organic ligand by forming metal ion-anion coordination with the release of the ligand $;^{7-9}$ (ii) "binding site-signaling subunit" protocol: the utilization of interactions between binding sites and the anions; ${ }^{10-12}$ and (iii) partial replacement of the bound ligand/ antenna, accompanied by the formation of a new organicmetal-anion adduct (Table S1 and Fig. S1 $\dagger$ ). ${ }^{13,14}$

Strategy (i) is a simple and convenient technique that has been used in a number of probes. However, most probes display only a "turn-on" or "turn-off" response to anions without any shift in the emission/absorption band. ${ }^{7-9}$ By contrast, the use of strategy (ii) is valuable because in many cases, it produces a ratiometric signal that can avoid most ambiguities, such as the interference of photobleaching and deviated microenvironments, local probe concentration, and experimental parameters, via the self-calibration of two absorption/emission bands. ${ }^{15}$ However, the design for ratiometric probes with two

School of Chemistry and Chemical Engineering, Guangxi University, Nanning 530004, P. R. China. E-mail: lwllhb@gxu.edu.cn; wjwyj82@gxu.edu.cn

$\dagger$ Electronic supplementary information (ESI) available. See DOI: $10.1039 / \mathrm{c} 8 \mathrm{ra00079d}$ remains extremely challenging. ${ }^{16,17}$ Thus, designing desirable metal-organic hybrid nano/micromaterials could be a difficult task if the absorption/emission ratiometric response could be observed at long wavelengths. Strategy (iii) represents a conceptually valuable addition to anion sensing. However, the reported single ligand-metal complexes are only focused on intensity-based responses (Table S1 and Fig. S1†). ${ }^{13,14}$ Different from the single ligand strategy, the mixed ligand strategy provides new opportunities for various fascinating applications. ${ }^{18}$ Following strategy (iii), could the cooperation of two different ligands in a metal complex-based system impart synergistic properties, such as ratiometric response in a visible range? To the best of our knowledge, no study has attempted to answer this question.

Bearing the aforementioned ideas in mind, we synthesized a cobalt metal-mixed organic complex-based hybrid

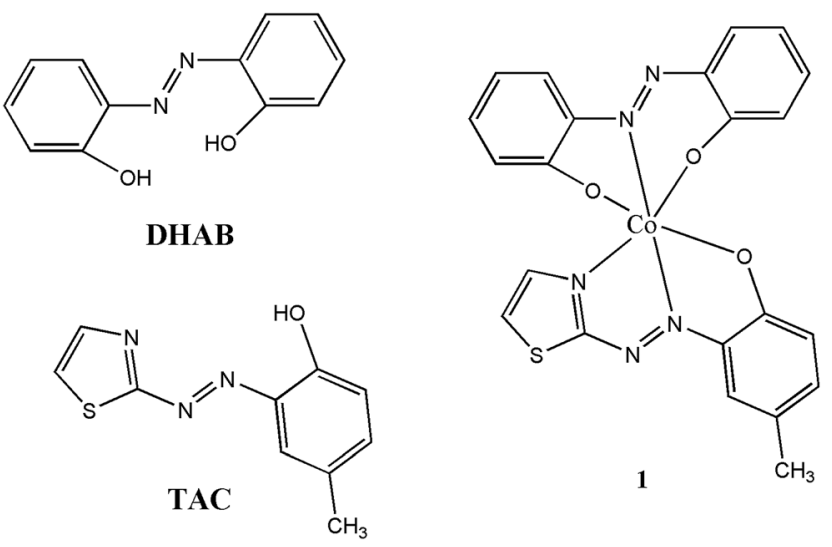

Fig. 1 Chemical structures of 2,2'-dihydroxyazobenzene (DHAB), 2(2-thiazolylazo)-p-cresol (TAC) and complex 1. 
micromaterial, DHAB(Co)TAC (1) (Fig. 1, DHAB = 2,2'-dihydroxyazobenzene, TAC $=2$-(2-thiazolylazo)- $p$-cresol), and demonstrated its application in detecting $\mathrm{CN}^{-}$. A mixed ligand of 2-hydroxyazobenzene derivatives, ${ }^{19}$ DHAB and TAC, was chosen in this work for the following reasons. (a) The mixed ligand provides synergistic coordination with metal ions, considering the deprotonation process $\left(\mathrm{p} K_{\mathrm{a}}\right)$ of hydroxyl groups $^{\mathbf{2 0 , 2 1}}$ to make the metal-oxygen bonds. Such process is a critical factor in the formation of metal-organic complexes. $^{22,23}$ Moreover, (b) the difference in the binding affinities of DHAB and TAC to metal ions is the basis for the selective recognition of anions based on strategy (iii) to shift the signal response to a long wavelength.

Compared to most reported $\mathrm{CN}^{-}$sensors ${ }^{7-14}$ and our previous work ${ }^{\mathbf{1 6}}$ based on metal-organic complexes, this study displayed several promising properties (Table $S 1 \dagger$ ): (1) ratiometric absorption response at two visible wavelengths $\left(A_{456} \mathrm{~nm} /\right.$ $\left.A_{537} \mathrm{~nm}\right)$, (2) the detection limit for $\mathrm{CN}^{-}$was lower than the maximum allowable level set by the World Health Organization $(1.9 \mu \mathrm{M})$ and the US Environmental Protection Agency (7.6 $\mu \mathrm{M}),{ }^{13,14}$ (3) $\mathrm{CN}^{-}$can be successfully differentiated from $\mathrm{S}^{2-}$, a common interference for the recognition of $\mathrm{CN}^{-},{ }^{9}$ and (4) $\mathrm{CN}^{-}$ could be detected over a wide $\mathrm{pH}$ range of 2.5-9.5.

\section{Experimental}

\subsection{Materials and instruments}

All reagents were obtained from commercial suppliers and used as received unless otherwise noted. All anions were used as sodium salts. The Fourier transform infrared (FTIR) spectra were recorded using a Nicolet iS50 spectrometer preparing $\mathrm{KBr}$ disk. The powder X-ray diffraction (PXRD) patterns were obtained with a Rigaku D/max-2500 diffractometer using CuK $\alpha$ radiation. The morphologies were obtained with a scanning electron microscope (SEM, Hitachi SU8020). Mass spectra were recorded on a UPLCICLASS-XEVOG2-XS QTOF mass spectrometer in acetonitrile. Absorption spectra were determined via UV 1901 spectroscopy (Shanghai Lengguang Technology Co., Ltd., China). Fluorescence spectra were determined with 960 MC spectroscopy (Shanghai Lengguang Technology Co., Ltd., China). A Mettler Toledo S20K $\mathrm{pH}$ meter was used to measure the $\mathrm{pH}$ of the solution, which was adjusted using either $0.1 \mathrm{M} \mathrm{HCl}$ or $\mathrm{NaOH}$ solution. All spectral studies were performed in 0.1 M HEPES buffered aqueous DMF medium (DMF-HEPES buffer solution, 4/1, v/v).

\subsection{Synthesis of DHAB(Co)TAC (1)}

An aqueous solution of $\mathrm{CoSO}_{4} \cdot 7 \mathrm{H}_{2} \mathrm{O}(0.4530 \mathrm{~g}, 1.612 \mathrm{mmol}, 50 \mathrm{~mL})$ was added dropwise over $30 \mathrm{~min}$ to a magnetically stirred solution of DHAB $(0.1714 \mathrm{~g}, 0.800 \mathrm{mmol})$ and TAC $(0.1754 \mathrm{~g}, 0.800 \mathrm{mmol})$ in $100 \mathrm{~mL}$ ethanol. The mixture was stirred at room temperature for $3 \mathrm{~h}$. The precipitate was collected by centrifugation and washed with water and absolute ethanol several times. Subsequently, these precipitates were dried under vacuum, and a deep black-brown colored product was obtained (0.3552 g, $0.725 \mathrm{mmol}, 90.6 \%$ yield). FTIR spectra (KBr, $\nu, \mathrm{cm}^{-1}$, Fig. S2 $\dagger$ ): 2379, 1500, 1467, 1430,
1405, 1361, 1329, 1303, 1214, 1190, 1147, 1132, 1022, 896. QTOFMS ES+ (Fig. S3†): found $m / z=490.08$ (calculated 490.03).

\section{Results and discussion}

\subsection{Characterization of 1}

In the infrared spectroscopy (Fig. $\mathrm{S} 2 \dagger$ ), the $\mathrm{O}-\mathrm{H}$ stretching frequency at $3432 \mathrm{~cm}^{-1}$ for the non-coordinated DHAB and TAC disappeared, thus indicating that DHAB and TAC deprotonated during coordination with cobalt ions by forming $\mathrm{Co}-\mathrm{O}$ bands. The peak at $896 \mathrm{~cm}^{-1}$ corresponded to the characteristic vibration of Co-N. ${ }^{24}$ The positive-ion peak in the ESI-MS (Fig. S3†) was observed at $\mathrm{m} / z 490.08$ (calculated 490.03). These phenomena indicated that $\mathrm{Co}^{2+}$ coordinated with the nitrogen and oxygen atoms of the phenolic group in the formation of $\mathrm{DHAB}(\mathrm{Co}) \mathrm{TAC}$ complex (1) with $1: 1$ : 1 stoichiometry (mole ratio) between $\mathrm{DHAB}$, TAC, and $\mathrm{Co}^{2+}$ (Fig. 1). The sharp, highly intense, and less diffused peaks in the PXRD patterns indicated that the prepared complex 1 was highly crystalline (Fig. S4 $\dagger$ ). The as-synthesized hybrid material 1 presented a microflake morphology, as indicated by the SEM images (Fig. 2a). Moreover, black-brown crystals of 1 were obtained via the slow evaporation of a DMF solution of $\mathbf{1}$ for a week. The crystal of $\mathbf{1}$ exhibited a hexangular microflake morphology, as observed using the SEM images (Fig. 2b) and optical microscope using a digital camera (inset of Fig. 2b).

\subsection{Optical response of 1 to anions}

As shown in Fig. 3a, the hybrid micromaterial 1 showed absorption bands at $330 \mathrm{~nm}, 405 \mathrm{~nm}, 508 \mathrm{~nm}$ (shoulder peak), $537 \mathrm{~nm}, 695 \mathrm{~nm}$ and $765 \mathrm{~nm}$ in the DMF-HEPES buffer solutions $(4 / 1, \mathrm{v} / \mathrm{v}, \mathrm{pH} 7.0)$. The synergistic coordination of DHAB and TAC with $\mathrm{Co}^{2+}$ led to the absorption band extending to the red region with $\lambda_{\max }$ at $695 \mathrm{~nm}$ and $765 \mathrm{~nm}$ (Fig. S5†), possibly because of the intramolecular charge transfer (ICT) from the sulfur atom on thiazole to the cobalt complex. ${ }^{24-26}$

The absorption spectra of $1(20 \mu \mathrm{M})$ upon the addition of 50 equiv. $\mathrm{CN}^{-}$showed a complete disappearance of the ICT band at both $695 \mathrm{~nm}$ and $765 \mathrm{~nm}$, with a new absorption band appearing at $456 \mathrm{~nm}$ (Fig. 3a) and consequently exhibiting a color change from dark pink to reddish orange (Fig. 3b), which was visible to the naked eye. The addition of $\mathrm{S}^{2-}$ and $\mathrm{SO}_{3}{ }^{2-}$ only caused increased or decreased absorption at $330 \mathrm{~nm}, 508 \mathrm{~nm}, 537 \mathrm{~nm}$,
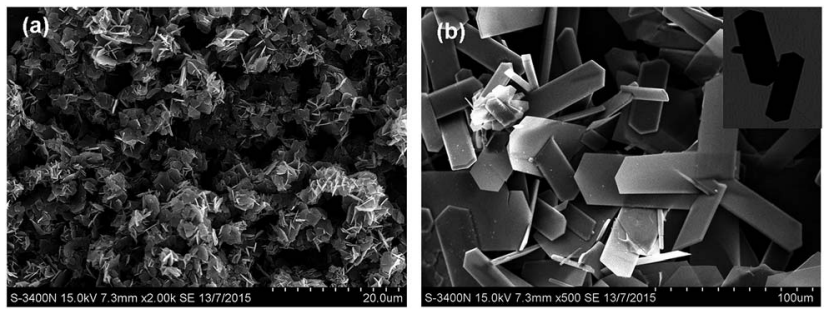

Fig. 2 SEM images of (a) microflakes of as-synthesized material 1 and (b) crystals of 1 with hexangular microflake morphology (inset showing the optical images). 


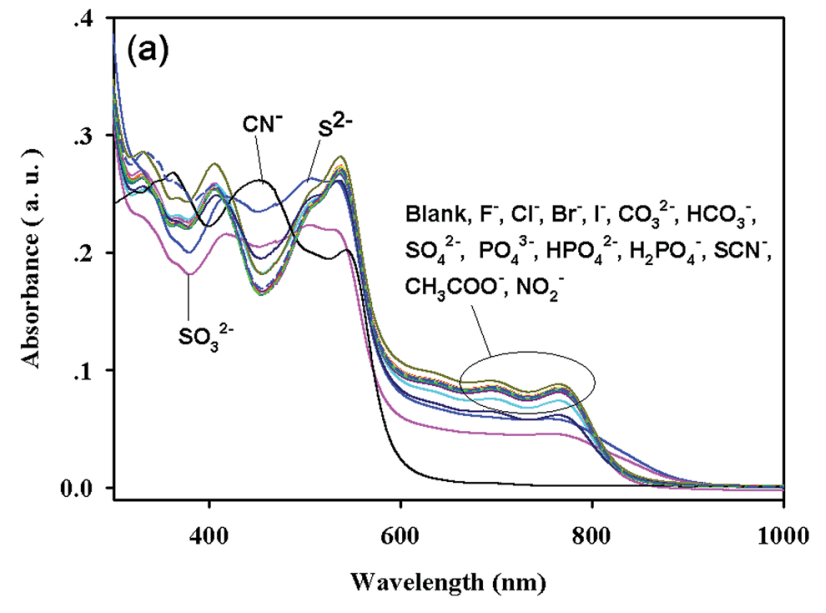

(b)

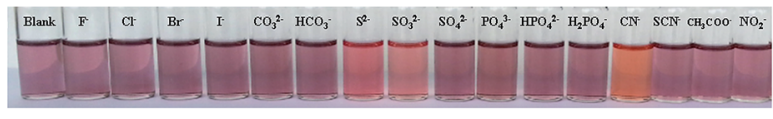

Fig. 3 (a) Absorption spectra and (b) visual color changes of 1 ( $2 \times$ $\left.10^{-5} \mathrm{M}\right)$ in the presence of various anions $\left(1.0 \times 10^{-3} \mathrm{M}\right)$ in DMFHEPES buffer solutions (4/1, v/v, $\mathrm{pH} 7.0)$.

$695 \mathrm{~nm}$ and $765 \mathrm{~nm}$, and a red shift of the band from $405 \mathrm{~nm}$ to $418 \mathrm{~nm}$ (Fig. 3a and S6†). An insignificant color change visible to the naked eye was also observed (Fig. 3b). By contrast, the addition of all other anions (50 equiv.), such as $\mathrm{F}^{-}, \mathrm{Cl}^{-}, \mathrm{Br}^{-}, \mathrm{I}^{-}, \mathrm{CO}_{3}{ }^{2-}$, $\mathrm{HCO}_{3}{ }^{-}, \mathrm{SO}_{4}{ }^{2-}, \mathrm{PO}_{4}{ }^{3-}, \mathrm{HPO}_{4}{ }^{2-}, \mathrm{H}_{2} \mathrm{PO}_{4}{ }^{-}, \mathrm{SCN}^{-}, \mathrm{CH}_{3} \mathrm{COO}^{-}$, and $\mathrm{NO}_{2}{ }^{-}$, to the solution of 1 caused negligible or no changes in the absorption spectra and solution colors (Fig. 3a and b). Therefore, $\mathbf{1}$ could detect $\mathrm{CN}^{-}$with specific selectivity.

\subsection{Sensitivity of 1 toward $\mathrm{CN}^{-}$}

Upon adding $\mathrm{CN}^{-}$to complex $\mathbf{1}$, the absorption intensity at $537 \mathrm{~nm}, 695 \mathrm{~nm}$ and $765 \mathrm{~nm}$ gradually decreased, and a new emission band centered at $456 \mathrm{~nm}$ gradually increased, with an isosbestic point appearing at $491 \mathrm{~nm}$. Then the absorption spectra reached the plateau at 10.0 equiv. of $\mathrm{CN}^{-}$, at which the bands at $695 \mathrm{~nm}$ and $765 \mathrm{~nm}$ vanished (Fig. 4a and S7†). Fig. 4b depicts the good linear relationship between the absorption intensity ratio $\left(A_{456 \mathrm{~nm}} / A_{537} \mathrm{~nm}\right)$ and the concentration of $\mathrm{CN}^{-}$in the range of 1.0-5.0 equiv. The UV-vis detection limit based on the ratio of $\mathrm{Abs}(456 \mathrm{~nm}) / \mathrm{Abs}(537 \mathrm{~nm})$ was calculated to be $1.8 \mu \mathrm{M}$.

The ability of a sensor to report only the desired analyte while ignoring competitors is crucial. To evaluate the $\mathrm{CN}^{-}$selective nature of complex 1, we performed competition experiments using solutions containing $\mathrm{CN}^{-}$and other anions, which we then compared with the solution containing $\mathrm{CN}^{-}$ only. These competition anions, which included $\mathrm{F}^{-}, \mathrm{Cl}^{-}, \mathrm{Br}^{-}$, $\mathrm{I}^{-}, \mathrm{CO}_{3}{ }^{2-}, \mathrm{HCO}_{3}{ }^{-}, \mathrm{S}^{2-}, \mathrm{SO}_{3}{ }^{2-}, \mathrm{SO}_{4}{ }^{2-}, \mathrm{PO}_{4}{ }^{3-}, \mathrm{HPO}_{4}{ }^{2-}, \mathrm{H}_{2} \mathrm{PO}_{4}{ }^{-}$, $\mathrm{SCN}^{-}, \mathrm{CH}_{3} \mathrm{COO}^{-}$, and $\mathrm{NO}_{2}{ }^{-}$, did not cause significant changes in the absorption spectra and color, as shown in Fig. S8. $\dagger$

\subsection{Effect of $\mathbf{p H}$}

For practical applications, the appropriate $\mathrm{pH}$ conditions for the successful operation of the sensor were evaluated. As shown
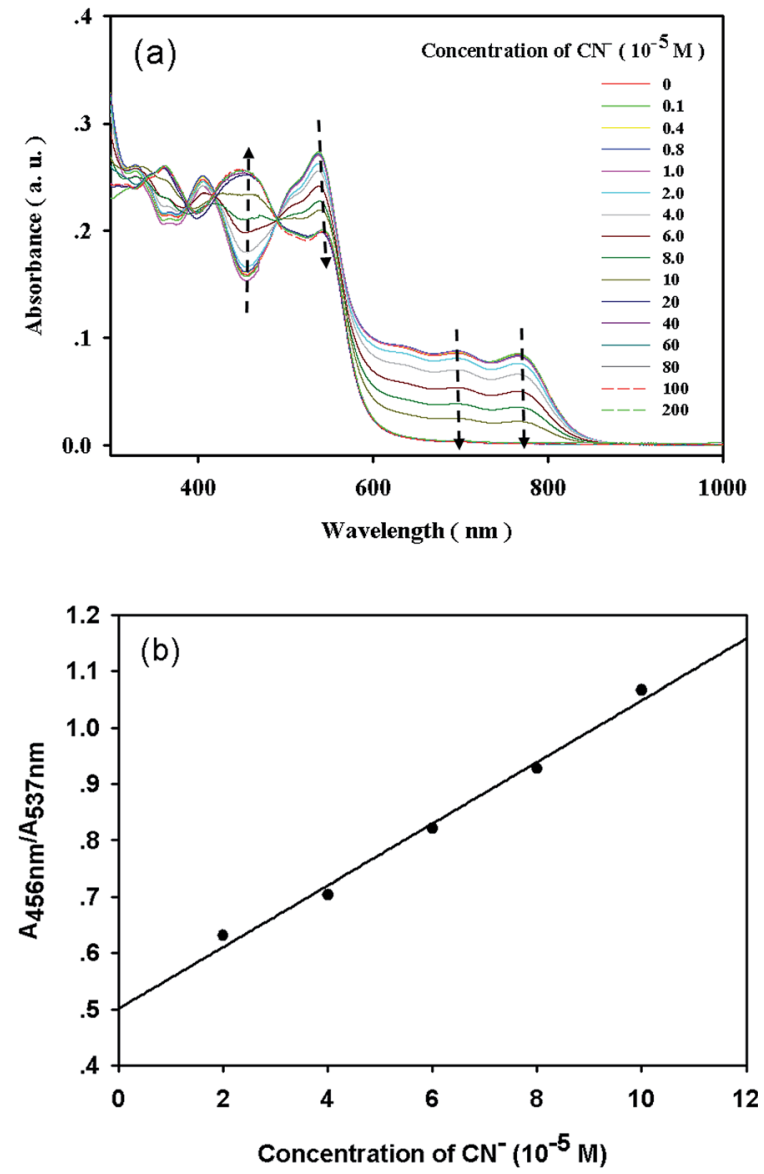

Fig. 4 (a) Absorption spectra of $1\left(2 \times 10^{-5} \mathrm{M}\right)$ upon titrating $\mathrm{CN}^{-}\left(0_{-}\right.$ $\left.2.0 \times 10^{-3} \mathrm{M}\right)$ and (b) absorption intensity ratio of $456 \mathrm{~nm}$ and $537 \mathrm{~nm}$ versus the concentration of $\mathrm{CN}^{-}$in DMF-HEPES buffer solutions (4/1, v/v, pH 7.0).

in Fig. 5, negligible or almost no pH effect on the UV-vis spectra and visual color of complex $\mathbf{1}$ was observed in a significantly wide $\mathrm{pH}$ range of 2.5-13.5, further indicating that all of the oxygen atoms in the phenolic groups were involved in the coordination with cobalt ions (Fig. 1). Over the $\mathrm{pH}$ range of 2.59.5, complex 1 in the presence of $\mathrm{CN}^{-}$displayed no obvious changes in absorption intensity, and the color remained reddish orange (Fig. 6). At $\mathrm{pH}$ values above 9.5, the absorption intensity at $550 \mathrm{~nm}$ increased drastically with concomitant color changes from reddish orange to bright pink by the naked eye, which was compatible with the $\mathrm{p} K_{\mathrm{a}}$ of the TAC molecule. ${ }^{20}$ The displacement of the coordinated TAC molecule from 1 and the changes in the absorption spectra could be attributed to the deprotonation of the phenolic group in TAC. Thus, 1 would have potential applications over the $\mathrm{pH}$ range of 2.5-9.5 in environmental analyses.

\subsection{Mechanism studies}

Initially, the sulfur atoms were capable of undergoing an ICT process, and consequently, complex 1 exhibited near-infrared (NIR) absorption bands at $695 \mathrm{~nm}$ and $765 \mathrm{~nm}$. The addition of $\mathrm{CN}^{-}$to 1 caused the disappearance of the ICT bands at both 


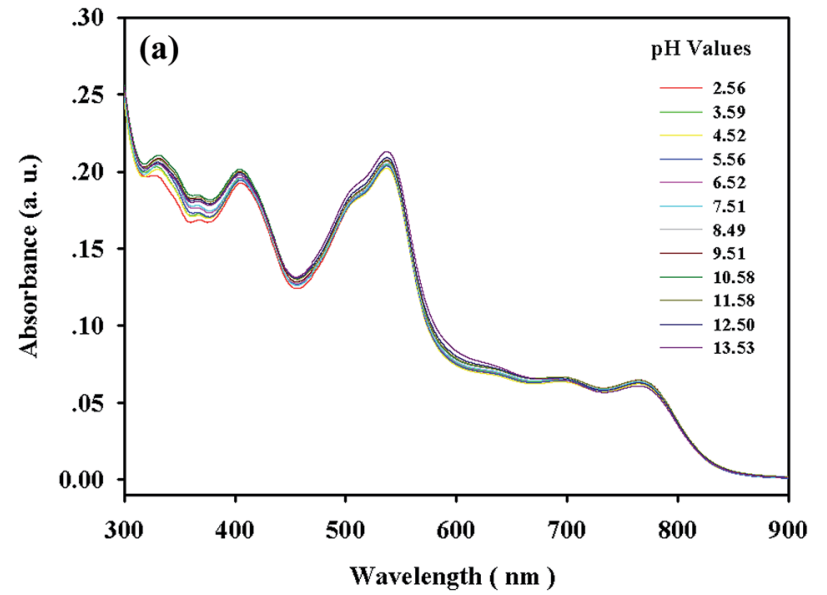

(b)

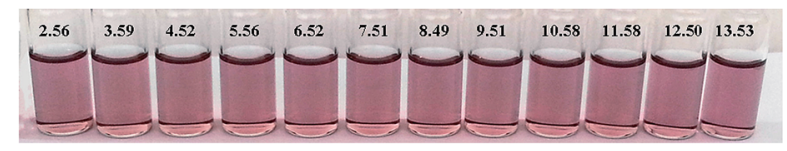

Fig. 5 (a) Absorption spectra and (b) visual colors of $1\left(2 \times 10^{-5} \mathrm{M}\right)$ at different $\mathrm{pH}$ values in DMF-HEPES buffer solutions $(4 / 1, \mathrm{v} / \mathrm{v})$.

$695 \mathrm{~nm}$ and $765 \mathrm{~nm}$ which could be attributed to the inhibition of ICT from the sulfur atoms to the cobalt complex. ${ }^{1}$ This result confirms our previous hypothesis that $\mathrm{CN}^{-}$induces TAC dissociation. This assumption verified by analyzing the UV-vis spectra (Fig. S9†). The changes in the absorption spectra induced by the addition of $\mathrm{CN}^{-}$are very similar to those observed in the absorption of TAC and DHAB- $\mathrm{Co}^{2+}$ in the

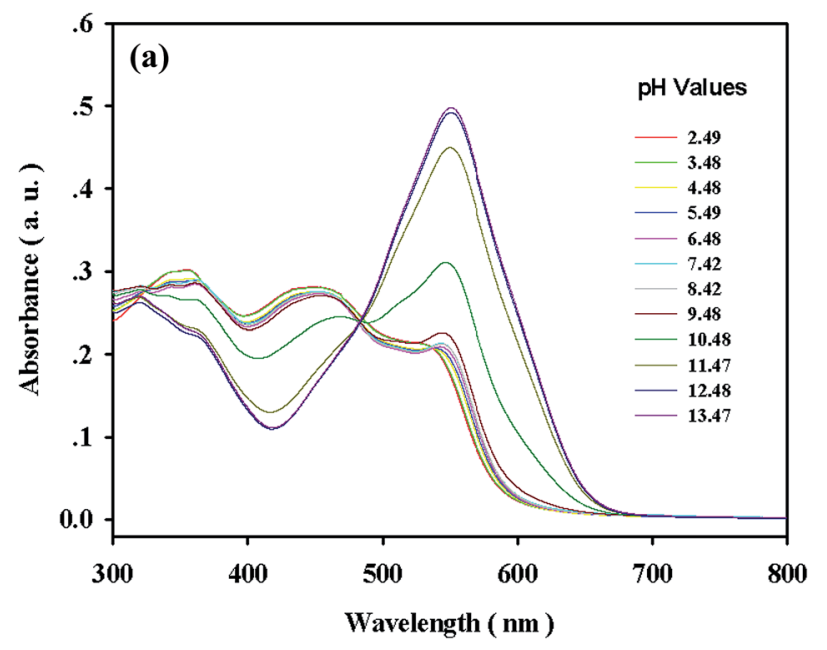

(b)

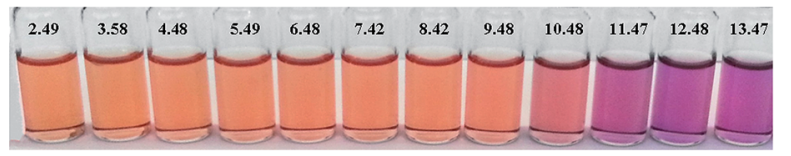

Fig. 6 (a) Absorption spectra and (b) visual colors of $1\left(2 \times 10^{-5} \mathrm{M}\right)$ with 10 equivalents of $\mathrm{CN}^{-}$at different $\mathrm{pH}$ values in DMF-HEPES buffer solutions $(4 / 1, \mathrm{v} / \mathrm{v})$. presence of $\mathrm{CN}^{-}$. In addition, TLC experiments also showed that TAC was released from 1 upon adding $\mathrm{CN}^{-}$(Fig. S10 $\dagger$ ). Moreover, mass spectra further confirmed the dissociation of TAC from complex $\mathbf{1}$, and then the formation of DHAB- $\mathrm{Co}^{2+}$ $\mathrm{CN}^{-}$species (Fig. S11 and S12 $\dagger$ ). The mass peaks at 218.1251 (calculated 218.3) and 270.9920 (calculated 270.2) correspond to TAC and DHAB- $\mathrm{Co}^{2+}$, respectively; and mass peaks observed at 339.2329 (calculated 337.3), 388.9708 (calculated 388.4), 451.1016 (calculated 449) and 480.0534 (calculated 479) are the adducts of DHAB(Co) $\left(\mathrm{CH}_{3} \mathrm{CN}\right)(\mathrm{CN}), \mathrm{DHAB}(\mathrm{Co})\left(\mathrm{CH}_{3} \mathrm{CN}\right)_{2}\left(\mathrm{H}_{2} \mathrm{O}\right)_{2}$, $\operatorname{DHAB}(\mathrm{Co})\left(\mathrm{CH}_{3} \mathrm{CN}\right)_{2}(\mathrm{CN})_{3}\left(\mathrm{H}_{2} \mathrm{O}\right)$, and $\mathrm{DHAB}(\mathrm{Co})\left(\mathrm{CH}_{3} \mathrm{CN}\right)_{4}(-$ $\mathrm{CN})\left(\mathrm{H}_{2} \mathrm{O}\right)$, respectively (Fig. S11 $\dagger$ ). The same $\mathrm{DHAB}-\mathrm{Co}^{2+}-\mathrm{CN}^{-}$ adducts was also found in the mass spectra of DHAB in the presence of $\mathrm{Co}^{2+}$ and $\mathrm{CN}^{-}$(Fig. $\mathrm{S} 12 \dagger$ ).

On the basis of the above findings, we can reliably assume that the coordination ability of $\mathrm{CN}^{-}$with $\mathrm{Co}^{2+}$ is much stronger than that of TAC. Therefore, $\mathrm{CN}^{-}$could competitively bind to $\mathrm{Co}^{2+}$ and release TAC from $1{ }^{8}$ whereas $\mathrm{DHAB}$ and $\mathrm{Co}^{2+}$ were strongly complexed and difficult to dissociate by $\mathrm{CN}^{-},{ }^{27}$ which coordinated with $\mathrm{DHAB}-\mathrm{Co}^{2+}$ by forming $\mathrm{DHAB}-\mathrm{Co}^{2+}-\mathrm{CN}^{-}$ (Fig. S13 $\dagger$ ). These experimental results indicated that the inhibition of the ICT band and the appearance of a new absorption band at $456 \mathrm{~nm}$ upon the addition of $\mathrm{CN}^{-}$involved the detaching of the TAC ligand, as well as the complexation of $\mathrm{CN}^{-}$ with the cobalt complex of DHAB instead of the dissociation of the DHAB ligand.

\section{Conclusions}

In conclusion, a microscale hybrid cobalt metal-mixed organic ligand material was synthesized, and $\mathrm{CN}^{-}$sensing properties were investigated. The anion-response selectivity and signalreporting properties are controlled by two key features. First, the rational introduction of two different organic ligands with synergistic coordination interaction and different coordination abilities to the metal center is crucial. Second, the competitive coordination of $\mathrm{CN}^{-}$and organic ligands with the metal center is required; in this case, the binding affinity of $\mathrm{CN}^{-}$with cobalt ion is lower than that of one organic ligand, but higher than that of the other organic ligand. This work provides an effective design rationale for the construction of ratiometric probes with two absorption signal ratios at two visible wavelengths. This work also provides an essential synthetic strategy in the design and synthesis of novel metal-mixed organic hybrid materials for selectively recognizing a desired target by fine-tuning ligands and metal ions.

\section{Conflicts of interest}

There are no conflicts to declare.

\section{Acknowledgements}

We thanks the NSFC (Grant No. 21567002, 31560014), GXNSFC (Grant No. 2015GXNSFCA139005), Hundred-Talent Program (Guangxi Province), the Scientific Research Foundation of 
Guangxi University (Grant No. XGZ130080 and XGZ130081) for financial support of this work.

\section{References}

1 J. Wang, H. B. Liu, Z. Tong and C. S. Ha, Coord. Chem. Rev., 2015, 303, 139-184.

2 J. Guo, Y. Ping, H. Ejima, K. Alt, M. Meissner, J. J. Richardson, Y. Yan, K. Peter, D. von Elverfeldt, C. E. Hagemeyer and F. Caruso, Angew. Chem., Int. Ed., 2014, 53, 5546-5551.

3 L. Chen, Q. Zhang, H. Xu, X. Hou, L. Xuan, Y. Jiang and Y. Yuan, J. Mater. Chem. A, 2015, 3, 1847-1852.

4 X. Hang, B. Liu, X. Zhu, S. Wang, H. Han, W. Liao, Y. Liu and C. Hu, J. Am. Chem. Soc., 2016, 138, 2969-2972.

5 S. H. Jung, K. Y. Kwon and J. H. Jung, Chem. Commun., 2015, 51, 952-955.

6 L. E. Santos-Figueroa, M. E. Moragues, E. Climent, A. Agostini, R. Martínez-Máñez and F. Sancenón, Chem. Soc. Rev., 2013, 42, 3489-3613.

7 (a) N. Busschaert, C. Caltagirone, W. V. Rossom and P. A. Gale, Chem. Rev., 2015, 115, 8038-8155; (b) J. Wu, B. Kwon, W. Liu, E. V. Anslyn, P. Wang and J. S. Kim, Chem. Rev., 2015, 115, 7893-7943.

8 (a) D. Wang, J. Q. Zheng, X. Yan, X. J. Zheng and L. P. Jin, RSC Adv., 2015, 5, 64756-64762; (b) K. H. Jung and K. H. Lee, Anal. Chem., 2015, 87, 9308-9314.

9 (a) T. D. Ashton, K. A. Jolliffe and F. M. Pfeffer, Chem. Soc. Rev., 2015, 44, 4547-4595; (b) R. Chandra, A. Ghorai and G. K. Patra, Sens. Actuators, B, 2018, 255, 701-711.

10 H. Lee, K. I. Hong and W. D. Jang, Coord. Chem. Rev., 2018, 354, 46-73.

11 F. Wang, L. Wang, X. Chen and J. Yoon, Chem. Soc. Rev., 2014, 43, 4312-4324.

12 C. Parthiban, S. Ciattini, L. Chelazzi and K. P. Elango, Sens. Actuators, B, 2016, 231, 768-778.
13 Z. Liu, W. He and Z. Guo, Chem. Soc. Rev., 2013, 42, 15681600.

14 I. Bhowmick, D. J. Boston, R. F. Higgins, C. M. Klug, M. P. Shores and T. Gupta, Sens. Actuators, B, 2016, 235, 325-329.

15 X. Li, X. Gao, W. Shi and H. Ma, Chem. Rev., 2014, 114, 590659.

16 (a) J. Wang and C. S. Ha, Analyst, 2011, 136, 1627-1631; (b) J. Wang and C. S. Ha, Tetrahedron, 2010, 66, 1846-1851.

17 Z. Shojaeifard, B. Hemmateenejad and M. Shamsipur, ACS Appl. Mater. Interfaces, 2016, 8, 15177-15186.

18 (a) Z. Yin, Y. L. Zhou, M. H. Zeng and M. Kurmoo, Dalton Trans., 2015, 44, 5258-5275; (b) H. B. Liu, H. Y. Zhao, Z. Tong, Y. Zhang, B. Lan and J. Wang, Sens. Actuators, B, 2017, 239, 511-514.

19 M. Emond, T. L. Saux, S. Maurin, J. B. Baudin, R. Plasson and L. Jullien, Chem.-Eur. J., 2010, 16, 8822-8831.

20 T. Momeni-Isfahani and A. Niazi, Spectrochim. Acta, Part A, 2014, 120, 630-635.

21 S. Saito, T. Anada, S. Hoshi and K. Akatsuka, Anal. Chem., 2005, 77, 5332-5338.

22 J. Jiang, Y. Zhao and O. M. Yaghi, J. Am. Chem. Soc., 2016, 138, 3255-3265.

23 F. I. El-Dossoki and F. A. El-Seify, J. Chem. Eng. Data, 2010, 55, 3572-3577.

24 J. Wang, H. B. Liu, W. Wang, I. Kim and C. S. Ha, Dalton Trans., 2009, 10422-10425.

25 A. Witt, F. W. Heinemann, S. Sproules and M. M. Khusniyarov, Chem.-Eur. J., 2014, 20, 11149-11162.

26 S. Y. Jiao, K. Li, W. Zhang, Y. H. Liu, Z. Huang and X. Q. Yu, Dalton Trans., 2015, 44, 1358-1365.

27 A. Zheng, D. A. Dzombak and R. G. Luthy, Environ. Sci. Technol., 2003, 37, 107-115. 